\title{
Increased Pain Sensitivity in Low Blood Pressure
}

\author{
S. Duschek, W. Schwarzkopf, and R. Schandry
}

University of Munich, Germany

\begin{abstract}
There is broad evidence for a functional interaction between the cardiovascular and pain regulatory systems. One result of this interaction is the reduced sensitivity to acute pain in individuals with elevated blood pressure, which has been established in numerous studies. In contrast to this, possible alterations in pain perception related to the lower range of blood pressure have not yet been investigated. In the present study pain sensitivity was assessed in 30 hypotensive women (mean blood pressure $95 / 56 \mathrm{mmHg}$ ) and 30 normotensive control persons (mean blood pressure $119 / 77 \mathrm{mmHg}$ ) based on a cold pressor test. Possible effects on pain perception of hypotension-related impairment of subjective state were controlled for by including a mood-scale. The hypotensive as compared to the normotensive group displayed lower pain threshold and pain tolerance levels, as well as increased sensory and affective experiences of pain. Moreover, a slight negative correlation was found, both in hypotensive and control persons, between pain sensitivity and the degree of blood pressure increase during the execution of the cold pressor test. In accordance with the previous findings on hypertension-related hypoalgesia, the present results suggest an inverse relationship between blood pressure and pain sensitivity across the total blood pressure spectrum. Different degrees of pain attenuation through afferent input from the arterial baroreceptor system are discussed as a physiological mechanism mediating this relationship.
\end{abstract}

Keywords: pain, blood pressure, hypotension, baroreceptor, cold pressor test

\section{Introduction}

Interactions between the cardiovascular and pain regulatory systems have constituted a major object of psychophysiological research since the late 1970s (Dworkin, Filewich, Miller, Craigmule, \& Pickering, 1979; Zamir \& Segal, 1979). A central observation of this line of inquiry is the inverse relationship between resting blood pressure and pain sensitivity. An association between clinic hypertension and hypoalgesia has been well established (Zamir \& Shuber, 1980; Ghione, 1996; France, 1999). Pain sensitivity is known to be diminished even in healthy subjects with only moderately elevated blood pressure (Fillingim \& Maixner, 1996; Myers, Robinson, Riley, \& Sheffield, 2001). In the normotensive population an inverse linear relationship between resting blood pressure and pain sensitivity has been repeatedly documented (Bruehl, Carlson, \& McCubbin, 1992; McCubbin \& Bruehl, 1994; Bruehl, Chung, Ward, Johnson, \& McCubbin, 2002).

Given such extensive evidence for a blood pressure-pain relationship in the normotensive and hypertensive spectra, it is somewhat surprising that research investigating an association in the lower blood pressure range has not yet been conducted. Overall, knowledge concerning the impact of reduced blood pressure on physical and mental functioning remains sparse (Duschek \& Schandry, 2006a, 2007). This may be largely explained by the fact that - in contrast to elevated blood pressure - hypotension is generally regarded neither as a medical condition nor as a risk factor for further disease. Nonetheless, it is typically associated with such symptoms as fatigue, reduced drive, faintness, dizziness, headache, and cold limbs, which can have a considerable impact on subjective well-being and quality of life (Wessely, Nixon, \& Cox, 1990; Pilgrim, Stansfield, \& Marmot, 1992; Rosengren, Tibblin, \& Wilhelmsen, 1993). The clinical relevance of the blood pressure-pain relationship is underlined by reports on an inverse association between blood pressure and the prevalence of pain syndromes in the normotensive and hypertensive ranges (e.g., Hagen et al., 2002, 2005). On this account, one may hypothesize that hypotensive individuals are more prone to clinical pain, which could also represent significant reduction in their quality of life.

According to the WHO (1978), hypotension is to be diagnosed when systolic blood pressure falls below $100 \mathrm{mmHg}$ in women and $110 \mathrm{mmHg}$ in men. In order to enhance clinical knowledge about hypotension, the present study investigated pain perception in this population. Moreover, the study addressed the more basic question whether the inverse blood pressure-pain relationship found for the normotensive and hypertensive ranges can be generalized to the complete blood pressure spectrum. This question is not trivial, insofar as associations between blood pressure and a variety of psychophysiological parameters are known to be nonlinear (Duschek \& Schandry, 2006a, 2007). For instance, the relationship between blood pressure and cognitive functioning is an inverted $\mathrm{u}$-shape with a decline of performance at both ends of the spectrum (Qiu, Winblad, \& Fratiglioni, 2005; Waldstein, Giggey, 
Table 1. Systolic blood pressure, diastolic blood pressure, heart rate, age, body mass index, mood scores on the Bf-S in both samples: means $(M)$, standard deviations $(S D)$, minimal (Min) and maximal (Max) values, $t$ and $p$ values for the group comparison.

\begin{tabular}{|c|c|c|c|c|c|c|c|c|c|c|}
\hline & \multicolumn{4}{|c|}{ Hypotensives } & \multicolumn{4}{|c|}{ Normotensive controls } & \multicolumn{2}{|c|}{ Group comparison } \\
\hline & $M$ & $S D$ & Min & $\operatorname{Max}$ & $M$ & $S D$ & Min & Max & $t$ & $p$ \\
\hline Systolic blood pressure in $\mathrm{mmHg}$ & 95.4 & 3.7 & 85.0 & 100.0 & 119.2 & 3.4 & 115.0 & 127.0 & -25.3 & $<.01$ \\
\hline Diastolic blood pressure in $\mathrm{mmHg}$ & 56.2 & 5.0 & 45.0 & 65.0 & 77.1 & 6.5 & 65.3 & 92.0 & -14.0 & $<.01$ \\
\hline Heart rate & 67.7 & 11.10 & 47.7 & 88.7 & 76.1 & 12.7 & 52.7 & 100.7 & -2.7 & $<.01$ \\
\hline Age in years & 25.4 & 4.7 & 20.0 & 38.0 & 23.5 & 2.6 & 20.0 & 29.0 & 2.0 & .05 \\
\hline Body mass index in $\mathrm{kg} / \mathrm{m}^{2}$ & 20.4 & 2.2 & 17.0 & 26.5 & 21.9 & 3.1 & 17.1 & 29.7 & -2.3 & .03 \\
\hline Mood scores (Bf-S) & 12.4 & 9.3 & 1 & 40 & 11.3 & 7.4 & 1 & 31 & 0.5 & .61 \\
\hline
\end{tabular}

Higher values on the Bf-S represent less favorable states of mood.

Thayer, \& Zonderman, 2005). Furthermore, cortical activation processes, as well as cerebral blood flow have been found to be reduced both in individuals with elevated and with low blood pressure (Baumbach \& Heistad, 1988; Hajdu \& Baumbach, 1994; Duschek \& Schandry, 2004, 2006b; Duschek, Meinhardt, \& Schandry, 2006).

In the present study pain sensitivity of hypotensive and normotensive individuals was compared using a cold pressor test (Wolff, 1984; Edens \& Gil, 1995). This is a reliable method of inducing pain, which has been shown to be sensitive to blood pressure-related differences (Keogh \& Witt, 2001). The main hypothesis implied an association of hypotension with a stronger subjective experience of pain, as well as reduced pain threshold and pain tolerance levels.

\section{Methods}

\section{Participants}

Thirty hypotensive and 30 normotensive control persons participated. Because of the higher prevalence of hypotension in the female population (e.g., Duschek \& Schandry, 2005) and known gender effects on pain sensitivity (e.g., Fillingim \& Maixner, 1996; Riley, Robinson, Wise, Myers, \& Fillingim, 1998), the sample was restricted to women.

Criteria for exclusion comprised severe physical diseases, acute or chronic pain of any kind, psychiatric disorders, as well as the use of psychoactive drugs, analgesics or medication affecting the cardiovascular system. Eight participants of the hypotensive and 12 of the control group reported that they currently used oral contraceptives $(U=390, p$ $=.28$ ). All participants were right-handed according to the Edinburgh Handedness Inventory (Oldfield, 1971). The sample consisted exclusively of university students. Information regarding blood pressure and heart rate recorded directly before the experimental procedure, age, body mass index (BMI, $\mathrm{kg} / \mathrm{m}^{2}$ ) and scores on the applied mood scale (see section Assessment Instruments) within the hypotensive and control samples is presented in Table 1. The table also provides the results of statistical group comparisons by means of $t$-tests.

\section{Pain Induction}

The cold pressor test entailed subjects immersing their left hand and forearm in ice-cold water, maintained at a temperature between $0^{\circ}$ and $3^{\circ} \mathrm{C}$. Participants were instructed to verbally indicate at what point they began to feel pain (pain threshold), and to withdraw from the ice-water when they could no longer tolerate the pain (pain tolerance threshold). An upper time limit of 3 min was set, because the hand usually goes numb after this point and pain sensations decrease (Wolff, 1984; Keogh \& Witt, 2001). ${ }^{1}$ Subjects were, however, not informed of this upper time limit. In order to control for possible effects of a lower skin temperature in hypotension (Stegagno, Angrilli, Costa, \& Palomba, 1996), subjects placed their left hand and forearm in a water bath of $37^{\circ} \mathrm{C}$ for $3 \mathrm{~min}$ immediately prior to the cold pressor test.

\section{Assessment Instruments}

The time span between immersion of the hand into ice-cold water and the first pain sensation, as well as between immersion and withdrawal of the hand were taken as measures for pain threshold and pain tolerance, respectively. In order to assess the participants' subjective experience of pain, they were presented with two $10-\mathrm{cm}$ line visual analog scales (VAS) referring to the sensory and affective aspects of pain ("How strong/unpleasant was the pain?"). The anchor points of the scales were marked not at all and extremely. Subjects were asked to rate the strongest pain sensation experienced in the course of the procedure.

In order to control for possible effects of mood on pain

\footnotetext{
1 The time limit was reached by four hypotensive and four normotensive participants. Because the data from these subjects could not be included in the statistical analysis, eight more subjects had to be recruited, meaning that there was a total of 68 subjects.
} 
sensitivity, the Befindlichkeits-Skala [Bf-S] (von Zerssen, 1976) was administered. This 28 -item self-rating scale includes positive and negative adjectives that are related to general aspects of well-being (e.g., cheerful, relaxed), as well as to more specific emotions (e.g., depressed, insecure). This instrument has been shown to be sensitive to the negative state of mood associated with hypotension (Duschek, Matthias, \& Schandry, 2005).

Blood pressure was continuously recorded during performance of the cold pressor test using a Finapres $2300 \mathrm{BP}$ Monitor (Ohmeda, Louisville, KY, USA). This technique has been shown to be reliable, particularly in assessing changes in blood pressure under defined conditions (Molhoek et al., 1983; Pickering \& Blank, 1989). The automatic recalibration feature of the Finapres system was enabled during testing.

\section{Procedure}

Assignment of subjects to the two groups was carried out on the basis of blood pressure readings taken in a screening session that was conducted at least one week prior to the main experiment and again at the beginning of the experimental session. Here, after a rest period of $10 \mathrm{~min}$, three sphygmomanometric blood pressure measurements were taken in a sitting position. For this purpose a regularly calibrated, automatic inflation monitor (TYP M CR15; Omron, MIT, Mannheim, Germany) was used. Readings were separated by 5 -min rest intervals. Subjects with a mean systolic blood pressure of less than $100 \mathrm{mmHg}$ were placed in the hypotensive group. The inclusion criterion for the control group was a systolic blood pressure between 115 and $140 \mathrm{mmHg}$. The respective criteria had to be fulfilled at both the screening and experimental sessions.

Participants gave their informed consent prior to the experiment. All sessions were conducted by a male experimenter. In order to prevent experimenter effects, instructions for the cold pressor test were presented in written form. Subjects were requested not to drink alcohol or beverages containing caffeine for $3 \mathrm{~h}$ before the screening and experimental sessions. They were paid EUR 15 for participation in the study.

\section{Data Analysis}

Statistical analysis included a multivariate analysis of variance (MANOVA) with hypotensive vs. control group as between-subjects factor. Dependent variables were pain threshold, pain tolerance, and the VAS ratings on subjective pain intensity. The groups differed considerably with regard to their BMI. In order to control for a possible effect of the content of fat tissue of the immersed hand on cold pressure pain, the BMI was included as a covariate in the MANOVA.

Linear associations between blood pressure and the measures of pain sensitivity were determined by means of Pearson correlations. In order to control for a possible third variable effect, the BMI was partialed out. The groups did not differ in the mood scores (Bf-S) and the Bf-S was not correlated with blood pressure $(r=.00$ for systolic blood pressure, $r=-.01$ for diastolic blood pressure, both $n s$ ). Therefore, mood was not used as a control variable either in the MANOVA or the correlation analysis.

The continuously recorded blood pressure values were averaged across both the 3 min warm water period (baseline) and the phase of ice-cold water stimulation. In order to evaluate blood pressure changes during stimulation, a repeated measures analysis of variance (ANOVA) was performed with time of measurement (baseline vs. stimulation) as within-subjects factor and group (hypotensive vs. control group) as between-subjects factor. Because of the possibility of confounding blood pressure change with the time that the subjects kept their hands in the water, this time span was used as a covariate.

Moreover, blood pressure changes between both periods were related to the pain measures. Pearson correlations were, therefore, calculated over the total sample, as well as separately for hypotensive and control subjects.

\section{Results}

\section{Group Differences in Pain Measures}

As depicted in Figure 1 both pain threshold and pain tolerance were lower in the hypotensive as compared with the normotensive group. The MANOVA with BMI controlled revealed a significant effect of blood pressure-group on both variables, pain threshold: $F(1 / 57)=4.97, p=.030$; pain tolerance: $F(1 / 57)=4.16, p=.046$. Ratings of subjective pain experience on the VAS were significantly higher in the hypotensive group (see Figure 2). This was the case

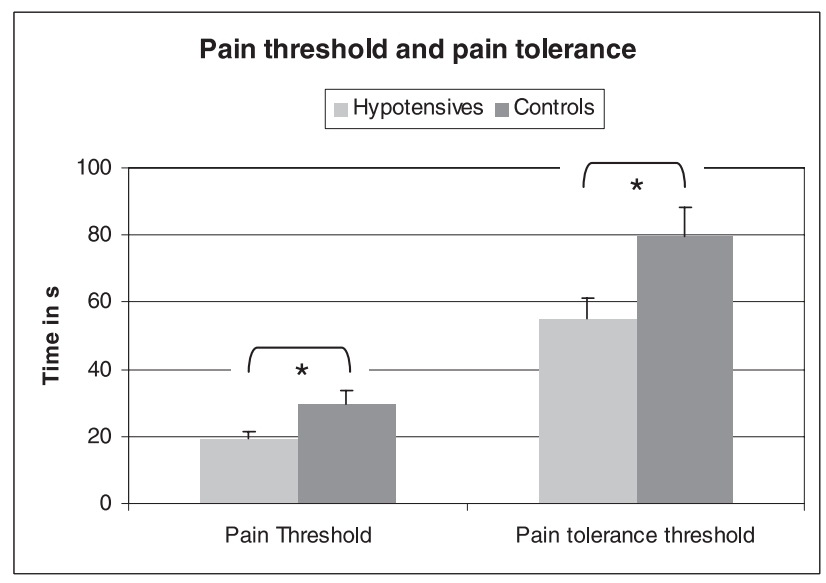

Figure 1. Pain threshold and pain tolerance in hypotensive and control subjects (bars represent standard errors, $* p<$ $.05)$. 


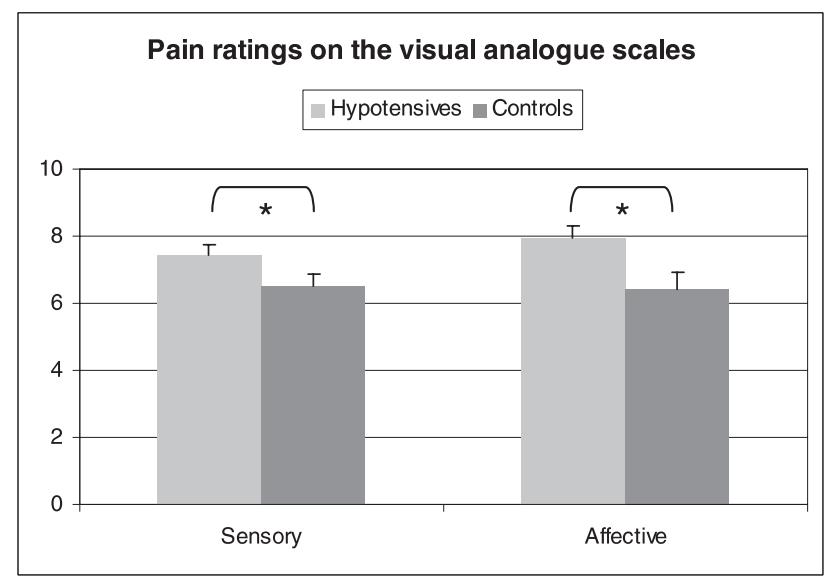

Figure 2. VAS ratings on the sensory and affective aspects of pain in hypotensive and control subjects (bars represent standard errors, $* p<.05)$.

for sensory, $F(1 / 57)=4.14, p=.046$, as well as affective aspects, $F(1 / 57)=5.35, p=.024$, of pain.

\section{Linear Associations Between Blood Pressure and Pain Measures}

Pearson correlations between blood pressure and measures of pain sensitivity with BMI partialed out are provided in Table 2. Pain threshold and pain tolerance were significantly positively correlated to systolic and diastolic blood pressure. Significant negative correlations were found between VAS ratings of sensory and affective pain experiences and both blood pressure parameters.

Table 2. Correlations between blood pressure and measures of pain sensitivity for the total sample with BMI partialed out $(* p<.05, * * p<.01)$

\begin{tabular}{lllll}
\hline & $\begin{array}{l}\text { Pain } \\
\text { threshold }\end{array}$ & $\begin{array}{l}\text { Pain } \\
\text { tolerance }\end{array}$ & $\begin{array}{l}\text { VAS } \\
\text { sensory }\end{array}$ & $\begin{array}{l}\text { VAS } \\
\text { affective }\end{array}$ \\
\hline $\begin{array}{l}\text { Systolic blood } \\
\text { pressure }\end{array}$ & $.26^{*}$ & $.26^{*}$ & $-.31^{* *}$ & $-.27^{*}$ \\
$\begin{array}{l}\text { Diastolic blood } \\
\text { pressure }\end{array}$ & $.24 *$ & $.22^{*}$ & $-.32^{* *}$ & $-.25^{*}$ \\
\hline
\end{tabular}

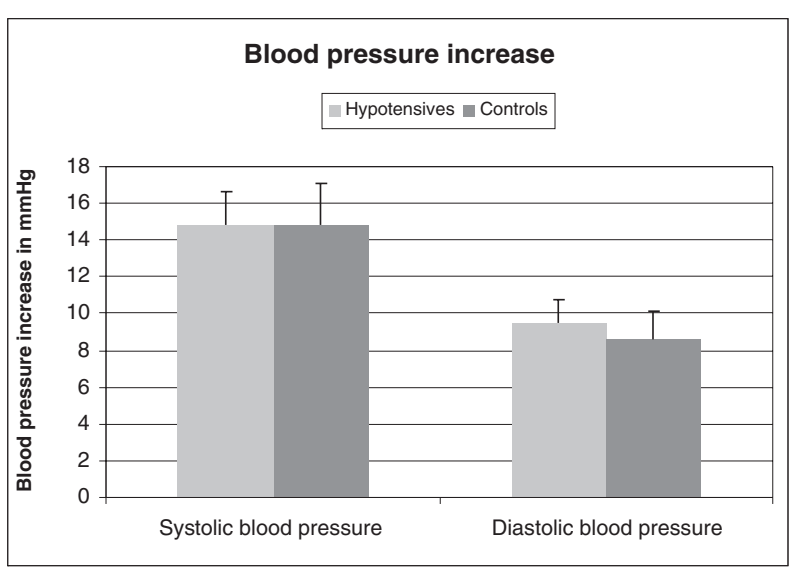

Figure 3. Blood pressure increase during the cold pressor test in hypotensive and control subjects (bars represent standard errors).

\section{Blood Pressure Changes During Cold Pressor Stimulation}

Both groups experienced a substantial increase in blood pressure during the cold pressor test (see Figure 3). This is underlined by a main effect of time of measurement (baseline vs. stimulation) on the blood pressure parameters with the time that the hand was kept in the water held constant, systolic blood pressure: $F[1 / 57]=12.63, p<.01$; diastolic blood pressure: $F[1 / 57]=10.05, p<.01)$. The magnitude of the blood pressure increase did not differ between groups, interaction between time of measurement and group: $F(1 / 57)=0.52, p=.48$ for systolic blood pressure, $F(1 / 57)=1.12, p=.29$ for diastolic blood pressure.

Table 3 displays the correlations between the increase in blood pressure and the measures of pain sensitivity. They were computed over the total sample, as well as separately for the hypotensive and the control groups. In the total sample the increases of both systolic and diastolic blood pressure were significantly correlated with pain tolerance. In the hypotensive group this association was limited to diastolic blood pressure, and in the control group to systolic blood pressure. Furthermore, significant negative correlations of systolic and diastolic blood pressure with the VAS ratings of the affective dimension of pain were found in the hypotensive group.

Table 3. Correlations between blood pressure increase during the cold pressor test and measures of pain sensitivity $(* p<$ $.05, * * p<.01)$

\begin{tabular}{|c|c|c|c|c|c|}
\hline & & Pain threshold & Pain tolerance & VAS sensory & VAS affective \\
\hline \multirow[t]{2}{*}{ Total sample } & Increase in systolic blood pressure & .09 & $.31 * *$ & -.12 & -.13 \\
\hline & Increase in diastolic blood pressure & .07 & $.25^{*}$ & .02 & -.08 \\
\hline \multirow[t]{2}{*}{ Hypotensives } & Increase in systolic blood pressure & -.12 & .26 & -.19 & $-.46 * *$ \\
\hline & Increase in diastolic blood pressure & -.03 & $.34 *$ & -.02 & $-.45 * *$ \\
\hline \multirow{2}{*}{$\begin{array}{l}\text { Normotensive } \\
\text { controls }\end{array}$} & Increase in systolic blood pressure & .18 & $.36 *$ & -.08 & .04 \\
\hline & Increase in diastolic blood pressure & .14 & .23 & .02 & .09 \\
\hline
\end{tabular}




\section{Discussion}

The present study demonstrated reduced pain threshold and pain tolerance levels, as well as an increased subjective experience of pain in individuals with low blood pressure. Moreover, an inverse linear association between blood pressure and pain sensitivity was found. The degree of blood pressure increase during the cold pressor test was positively related to pain tolerance and, in the case of the hypotensive group, inversely related to affective pain experience.

The current study extends knowledge concerning physical and mental aberrances related to low blood pressure. In addition to the well-known subjective symptoms (for review see Duschek \& Schandry, 2006a, 2007), previous research has revealed cognitive deficits in hypotension, particularly in terms of reduced attentional and memory performance (Stegagno et al., 1996; Duschek, Weisz, \& Schandry, 2003; Duschek et al., 2005). Psychophysiological studies have also yielded deficits in brain electric processes, as well as in the regulation of cerebral blood flow (Costa, Stegagno, Schandry, \& Bitti, 1998; Weisz, Schandry, Jacobs, Mialet, \& Duschek, 2002; Duschek et al., 2006; Duschek \& Schandry, 2004, 2006b, 2007). In a medical context, hypotension has been identified as a major risk factor in pregnancy (Harsanyi \& Kiss, 1985; Ng \& Walters, 1992; Warland \& McCutcheon, 2002). Several studies focusing on the elderly population have yielded associations between low blood pressure and the prevalence and incidence of dementia (e.g., Ruitenberg et al., 2001; Morris et al., 2002).

Several mechanisms must be considered as possibly underlying hypotension-related hyperalgesia. Since emotional state was controlled in our study, it is unlikely that the increased pain sensitivity resulted from impaired mood in hypotension. Furthermore, on account of the experimental procedure it can be ruled out that higher sensitivity to cold pain was an artifact of lower skin temperature.

Various physiological systems are assumed to be involved in mediating the interaction between cardiovascular activity and pain regulation. The arterial baroreceptor system plays a crucial role (for review see Rau \& Elbert, 2001). As sensors for blood pressure changes, the baroreceptors form part of a negative feedback loop compensating for phasic blood-pressure fluctuations (e.g., Dembowsky \& Seller, 1995; Guyton \& Hall, 2005). Various animal and human studies have shown that baroreceptor stimulation also attenuates pain sensitivity (Droste et al., 1994; Kardos et al., 1994; Rau et al., 1994; Bossut \& Maixner, 1996). This may be regarded as an adaptive homeostatic process in which a pain-related blood pressure increase leads to baroreceptor stimulation that in turn triggers pain inhibition, thereby helping to normalize arousal level (Bruehl \& Chung, 2004). In the present study this mechanism is reflected in inverse associations between the degree of rise in blood pressure during the cold pressor test and some of the measures of pain sensitivity.
The mechanism of pain attenuation through baroreceptor activation has also been proposed as an explanation of the inverse relationship between tonic blood pressure and pain sensitivity (e.g., Bruehl \& Chung, 2004). Here, hypertension-related hypoalgesia is seen to be a consequence of permanently enhanced baroreceptor stimulation (France, 1999; Rau \& Elbert, 2001). It has been pointed out that higher firing rates of the receptors not only result from increased resting blood pressure but also from enhanced blood pressure amplitude and cardiac output, both of which are typical for hypertension (Rau \& Elbert, 2001). In the case of low blood pressure, an inverse mechanism may be assumed, whereby a lack of pain attenuation as a consequence of persistently reduced baroreceptor stimulation stands to reason.

Several neurochemical systems have also been discussed as being involved in the interaction between hemodynamic conditions and nociception. Animal studies have demonstrated that endogenous opioid activity is necessary for a full expression of the inverse relationship between blood pressure and pain sensitivity (Zamir, Simantow, \& Segal, 1980; Maixner et al., 1982). However, human studies prove somewhat controversial, suggesting that the blood pressure-pain relationship can also occur in the absence of functionally active endogenous opioid systems (McCubbin \& Bruehl, 1994; Bruehl \& Chung, 2004). The central noradrenergic system is known to be of importance in blood pressure regulation (e.g., Carlson, 2004), as well as in descending pain inhibition (Millan, 2002). As neural interfaces underlying both cardiovascular and pain regulation, the nucleus of the solitary tract, the rostral ventrolateral medulla, and the locus coeruleus have, for example, been considered, all of which comprise noradrenergic pathways (Bruehl \& Chung, 2004). The crucial role of catecholaminergic mechanisms is also underlined by studies demonstrating that pharmacological blockade of adrenergic receptors reduces hypoalgesia resulting from baroreceptor stimulation (Randich \& Maixner, 1984; Ren, Randich, \& Gebhard, 1988).

One limitation of the present study may result from the relationship between cold pain and peripheral perfusion being mediated by a dependence of the activity of vascular nociceptors on blood flow (Fruhstorfer \& Lindblom, 1983; Klement \& Arndt, 1991). Considering this, pain enhancement as a consequence of reduced peripheral perfusion could occur in hypotension. Thus, it cannot be ruled out that, in addition to central nervous factors, peripheral mechanisms contribute to the mediation of the observed effect. The blood pressure groups also differed considerably with respect to their BMI. Even though the BMI was controlled for in the statistical analysis, a possible effect on pain of hand composition (i.e., a lower content of fat tissue in hypotension) cannot be completely ruled out. Further limitations of the study arise from the relatively small sample size and the fact that only female subjects were used, which might restrict the generalizability of the results.

Finally, possible clinical implications of the present 
findings should also be considered. The clinical significance of the blood pressure-pain relationship is underlined by an epidemiological study of Hagen et al. (2005). They found a $10 \%$ to $60 \%$ lower prevalence of chronic musculoskeletal complaints in individuals with hypertension, as well as an inverse linear relationship between blood pressure and occurrence of such symptoms. Elevated blood pressure, furthermore, predicted reduced risk of headache (Hagen et al., 2002). In a sample assessed for coronary heart disease, chest pain experienced during exercise was inversely related to blood pressure (Ditto, D'Antono, \& Dupuis, 2007). Also, postsurgical pain was found to correlate negatively with blood pressure (France \& Katz, 1999). On account of these studies and the current findings, one may assume that individuals with low blood pressure are more prone to clinical pain.

Empirical knowledge concerning the treatment of hypotension remains sparse (Duschek \& Schandry, 2006a, 2007). Some pioneering studies have shown that subjective hypotension-related symptoms can be reduced by pharmacological blood pressure elevation (Bismarck \& Rust, 1982; Schandry, 1999). Cerebral blood flow and cognitive performance may also be enhanced by these means (Duschek, Hadjamu, \& Shandry, 2007). However, the possibility of reducing pain sensitivity and prevalence of clinical pain through blood pressure elevation remains an open question.

In summing up, the present study yielded evidence that low blood pressure is accompanied by increased sensitivity to acute pain. Indeed, our results suggest that the inverse relationship between blood pressure and pain sensitivity, which has previously been documented for the normotensive and hypertensive ranges, can now be generalized to the complete blood pressure spectrum.

\section{Acknowledgments}

This study was partly financed by the German Research Foundation (Project-No.: SCHA 308/17-3). We are also very grateful to Katrin Holler and Jan Auracher for their help with the acquisition of the subjects.

\section{References}

Baumbach, G.L., \& Heistad, D.D. (1988). Cerebral circulation in chronic arterial hypertension. Hypertension, 12, 89-95.

Bismarck, M., \& Rust, G. (1982). Erste Erfahrungen mit dem Antihypotonikum Thomasin (= Etilefrin) unter ambulanten Bedingungen (eine Doppelblindstudie) [Initial experience with the anti-hypotensive agent Thomasin (= Etilefrin) in outpatients (a double-blind study)]. Zeitschrift für Ärztliche Fortbildung, 76, 153-156.

Bossut, D.F., \& Maixner, W. (1996). Effects of cardiac vagal afferent electrostimulation on the responses of trigeminal and trigeminothalamic neurons to noxious orofacial stimulation. Pain, 65, 101-109.
Bruehl, S., Carlson, C.R., \& McCubbin, J.A. (1992). The relationship between pain sensitivity and blood pressure in normotensives. Pain, 48, 463-467.

Bruehl, S., Chung, O.Y., Ward, P., Johnson, B., \& McCubbin, J.A. (2002). The relationship between resting blood pressure and acute pain sensitivity in healthy normotensives and chronic back pain sufferers: The effects of opioid blockade. Pain, 100, 191-201.

Bruehl, S., \& Chung, O.Y. (2004). Interactions between the cardiovascular and pain regulatory systems: An updated review of mechanisms and possible alterations in chronic pain. Neuroscience and Biobehavioral Reviews, 28, 395-414.

Carlson, N.R. (2004). Physiology of behavior. Harlow: Pearson Education.

Costa, M., Stegagno, L., Schandry, R., \& Bitti, P.E.R. (1998). Contingent negative variation and cognitive performance in hypotension. Psychophysiology, 35, 737-744.

Dembowsky, K., \& Seller, H. (1995). Arterial baroreceptor reflexes. In D. Vaitl \& R. Schandry (Eds.), From the heart to the brain: The psychophysiology of circulation-brain interaction (pp. 35-60). Frankfurt a.M.: Europäischer Verlag der Wissenschaften.

Ditto, B., D’Antono, B., \& Dupuis, G. (2007). Chest pain is inversely associated with blood pressure during exercise among individuals being assessed for coronary heart disease. Psychophysiology, 44, 183-188.

Droste, C., Kardos, A., Brody, S., Greenlee, M.W., Roskamm, H., \& Rau, H. (1994). Baroreceptor stimulation: Pain perception and sensory thresholds. Biological Psychology, 37, 101-113.

Duschek, S., Hadjamu, M., \& Schandry, R. (2007). Enhancement of cerebral blood flow and cognitive performance due to pharmacological blood pressure elevation in chronic hypotension. Psychophysiology, 44, 145-153.

Duschek, S., Matthias, E., \& Schandry, R. (2005). Essential hypotension is accompanied by deficits in attention and working memory. Behavioral Medicine, 30, 149-158.

Duschek, S., Meinhardt, J., \& Schandry, R. (2006). Reduced cortical activity due to chronic low blood pressure: An EEG study. Biological Psychology, 72, 241-250.

Duschek, S., \& Schandry, R. (2004). Cognitive performance and cerebral blood flow in essential hypotension. Psychophysiology, 41, 905-913.

Duschek, S., \& Schandry, R. (2005). Subjektive Beschwerden und kognitive Minderleistungen bei essentieller Hypotonie [Subjective complaints and reduced cognitive performance in essential hypotension]. Verhaltenstherapie und Verhaltensmedizin, 26, 5-31.

Duschek, S. \&, Schandry, R. (2006a). Antriebsschwäche und beeinträchtigte Hirnleistungen: Neue Perspektiven zum chronisch niedrigen Blutdruck [Reduced drive and cerebral performance: new perspectives on chronic low blood pressure]. Deutsche Medizinische Wochenschrift, 131, 272-277.

Duschek, S., \& Schandry, R. (2006b). Deficient adjustment of cerebral blood flow to cognitive activity due to chronically low blood pressure. Biological Psychology, 72, 311-317.

Duschek, S., \& Schandry, R. (2007). Reduced brain perfusion and cognitive performance due to essential hypotension. Clinical Autonomic Research, 17, 69-76.

Duschek, S., Weisz, N., \& Schandry, R. (2003). Reduced cognitive performance and prolonged reaction time accompany 
moderate hypotension. Clinical Autonomic Research, 13, 427-432.

Dworkin, B., Filewich, R., Miller, N., Craigmule, N., \& Pickering, T. (1979). Baroreceptor activation reduces reactivity to noxious stimulation: Implications in hypertension. Science, 205, 1299-1301.

Edens, J.L., \& Gil, K.M. (1995). Experimental induction of pain: Utility in the study of clinical pain. Behavior Therapy, 26, 197-216.

Fillingim, R.B., \& Maixner W. (1996). The influence of resting blood pressure and gender on pain responses. Psychosomatic Medicine, 58, 326-332.

France, C.R. (1999). Decreased pain perception and risk for hypertension: Considering a common physiological mechanism. Psychophysiology, 36, 683-692.

France, C., \& Katz, J. (1999). Postsurgical pain is attenuated in men with elevated presurgical systolic blood pressure. Pain Research and Management, 4, 100-103.

Fruhstorfer. H., \& Lindblom, U. (1983). Vascular participation in deep cold pain. Pain, 17, 235-241.

Ghione, S. (1996). Hypertension-associated analgesia. Hypertension, 28, 494-504.

Guyton, A.C., \& Hall, J.E. (2005). Textbook of medical physiology. Philadelphia: Saunders.

Hagen, K., Stovner, L.J., Vatten, L., Holmen, J., Zwart, J.-A., \& Bovim, G. (2002). Blood pressure and risk of headache: A prospective study of 22,685 adults in Norway. Journal of Neurology, Neurosurgery, and Psychiatry, 72, 463-466.

Hagen, K., Zwart, J.A., Holmen, J., Svebak, S., Bavim, G., \& Stovner, L.J. (2005). Does hypertension protect against chronic musculoskeletal complaints? The Nord-Trondelag Health Study. Archives of Internal Medicine, 165, 916-922.

Hajdu, M.A., \& Baumbach, G.L. (1994). Mechanisms of large and small cerebral arteries in chronic hypertension. American Journal of Physiology, 35, H1027-H1033.

Harsanyi, J., \& Kiss, D. (1985). Hypotonie in der Schwangerschaft [Hypotension during pregnancy]. Zentralblatt für Gynäkologie, 107, 363-369.

Kardos, A., Rau, H., Greenlee, M.W., Droste, C., Brody, S., \& Roskamm, H. (1994). Reduced pain during baroreceptor stimulation in patients with symptomatic and silent myocardial ischemia. Cardiovascular Research, 28, 515-518.

Keogh, E., \& Witt, G. (2001). Hypoalgesic effect of caffeine in normotensive men and women. Psychophysiology, 38, 886-895.

Klement, W., \& Arndt, J.O. (1991). Pain but no temperature sensations are evoked by thermal stimulation of cutaneous veins in man. Neuroscience Letters, 123, 119-122.

McCubbin, J.A., \& Bruehl, S. (1994). Do endogenous opioids mediate the relationship between blood pressure and pain sensitivity in normotensives? Pain, 57, 63-67.

Millan, M.J. (2002). Descending control of pain. Progress in Neurobiology, 66, 355-474.

Molhoek, P.G., Wesseling, K.H., Arntzenius, A.C., Settels, J.J., v. Vollenhoven, E., Weeda, H. Et al. (1983). Initial results of noninvasive measurement of finger blood pressure according to Penaz. Automedica, 4, 241-246.

Morris, M.C., Scherr, P.A., Hebert, L.E., Bennett, D.A., Wilson, R.S., Glynn, R.J. et al. (2002). Association between blood pressure and cognitive function in a biracial community population of older persons. Neuroepidemiology, 21, 123-130.

Myers, C.D., Robinson, M.E., Riley, J.L., \& Sheffield, D. (2001).
Sex, gender, and blood pressure: Contributions to experimental pain report. Psychosomatic Medicine, 63, 545-550.

Ng, P.H., \& Walters, W.A. (1992). The effect of chronic maternal hypotension during pregnancy. Australian and New Zealand Journal of Obstetrics and Gynecology, 32, 14-16.

Oldfield, R.C. (1971). The assessment and analysis of handedness: The Edinburgh inventory. Neuropsychologia, 9, 97-113.

Pickering, T.G., \& Blank, S.G. (1989). The measurement of blood pressure. In N. Schneiderman, S.M. Weiss, \& P. Kaufman (Eds.), Handbook of research methods in cardiovascular behavioral medicine (pp. 69-79). New York: Plenum.

Pilgrim, J.A., Stansfield, S., \& Marmot, M. (1992). Low blood pressure, low mood? British Medical Journal, 304, 75-78.

Qiu, C., Winblad, B., \& Fratiglioni, L. (2005). The age-dependent relation of blood pressure to cognitive function and dementia. Lancet Neurology, 4, 487-499.

Randich, A., \& Maixner, W. (1984). Interactions between cardiovascular and pain regulatory systems. Neuroscience and Biobehavioral Reviews, 8, 343-367.

Rau., H., Brody, S., Larbig, W., Pauli, P., Vohringer, M., Harsch, B. et al. (1994). Effects of PRES baroreceptor stimulation on thermal and mechanical pain threshold in borderline hypertensives and normotensives. Psychophysiology, 31, 480-485.

Rau, H., \& Elbert, T. (2001). Psychophysiology of arterial baroreceptors and the etiology of hypertension. Biological Psychology, 57, 179-201.

Ren, K., Randich, A., \& Gebhard, G.F. (1988). Vagal afferent modulation of a nociceptive reflex in rats: Involvement of spinal opioid and monoamine receptors. Brain Research, 446, 285-294.

Riley, J.L., Robinson, M.E., Wise, E.A., Myers, C.D., \& Fillingim, R.B. (1998). Sex differences in the perception of noxious experimental stimuli: A meta-analysis. Pain, 74, 181-187.

Rosengren, A., Tibblin, G., \& Wilhelmsen, L. (1993). Low systolic blood pressure and self-perceived well-being in middleaged men. British Medical Journal, 306, 243-246.

Ruitenberg, A., Skoog, I., Ott, A., Aevarsson, O., Witteman, J.C., Lernfelt, B. et al (2001). Blood pressure and risk of dementia: Results from the Rotterdam study and the Gothenburg H-70 study. Dementia and Geriatric Cognitive Disorders, 12, 33-39.

Schandry, R. (1999). Die Verbesserung der subjektiven Befindlichkeit bei orthostatischer Hypotonie unter dem Einfluss blutdrucksteigernder Therapie [Improvement of subjective state in orthostatic hypotension due to blood pressure enhancing treatment]. Medizinische Welt, 50, 160-165.

Stegagno, L., Angrilli, A., Costa, M., \& Palomba, D. (1996). Deficit cognitivi e ipotensione arteriosa: Un' indagine cronopsycofisiologica [Cognitive deficits and arterial hypotension: a chrono-psychophysiological approach]. Giornale Italiano di Psicologia, 23, 837-859.

von Zerssen, D. (1976). Klinische Selbstbeurteilungs-Skalen aus dem Münchner Psychiatrischen Informations-System (PSYCHIS) München. Die Befindlichkeitsskala [Clinical self-rating scales from the Munich Psychiatric Information System (PSYCHIS). The Scale on Subjective State]. Weinheim: Beltz.

Waldstein, S.R., Giggey, P.P., Thayer, J.F., \& Zonderman, A.B. (2005). Nonlinear relations of blood pressure to cognitive function: The Baltimore Longitudinal Study of Aging. Hypertension, 45, 374-379.

Warland, J., \& McCutcheon, H. (2002). Is there an association between maternal hypotension and poor pregnancy outcome? 
A review of contemporary literature. Australian College of Midwives Incorporated, 14, 22-26.

Weisz, N., Schandry, R., Jacobs, A., Mialet, J., \& Duschek, S. (2002). Early contingent negative variation of the EEG and attentional flexibility are reduced in hypotension. International Journal of Psychophysiology, 45, 253-260.

Wessely, S., Nickson, J., \& Cox, B. (1990). Symptoms of low blood pressure: A population study. British Medical Journal, 301, 362-365.

WHO. (1978). Arterial hypertension. Technical report series no. 628. Genova: World Health Organization.

Wolff, B.B. (1984). Methods of testing pain mechanisms in normal men. In D. Wall \& R. Melzack (Eds.), Textbook of pain (pp. 186-194). Edinburgh: Churchill Livingstone.

Zamir, N., \& Segal, M. (1979). Hypertension-induced analgesia: Changes in pain sensitivity in experimental hypertensive rats. Brain Research, 160, 170-173.

Zamir, N., \& Shuber, E. (1980). Altered pain perception in hypertensive humans. Brain Research, 201, 471-474.
Zamir, N., Simantow, R., \& Segal, M. (1980). Pain sensitivity and opioid activity in genetically and experimentally hypertensive rats. Brain Research, 184, 299-310.

Accepted for publication: Sept. 6, 2007

\section{Stefan Duschek}

Ludwig-Maximilians-Universität München

Department Psychologie

Leopoldstr. 13

D-80802 Munich

Germany

Tel. +49 $892180-5297$

Fax +49892180-5233

E-mailduschek@psy.uni-muenchen.de 